\title{
MELHORIA NA EFICIÊNCIA DA CLARIFICAÇÃO DE SUCO DE MARACUJÁ PELA COMBINAÇÃO DOS PROCESSOS DE MICROFILTRAÇÃO E ENZIMÁTICO
}

\author{
BRENO DE PAULA * \\ INGRID V.M. MORAES * \\ CAROLINA C. CASTILHO * \\ FLÁVIA DOS SANTOS GOMES ** \\ VIRGÍNIA MARTINS DA MATTA *** \\ LOURDES MARIA CORRÊA CABRAL ****
}

\begin{abstract}
Este trabalho teve como objetivo a obtenção de suco clarificado de maracujá, utilizando a técnica de microfiltração. Introduziu-se a etapa de tratamento enzimático antes da microfiltração, visando aumentar a eficiência do processo pela redução da viscosidade e do teor de polpa do suco. Foram testadas três diferentes enzimas hidrolíticas em três níveis de concentração. Os resultados não mostraram diferenças significativas quanto ao Brix, $\mathrm{pH}$ e acidez das amostras de suco hidrolisado em relação ao suco integral. Observou-se efeito positivo da ação das enzimas na redução da viscosidade e do teor de polpa. A microfiltração foi realizada em sistema de membrana tubular com tamanho médio de poro equivalente a $0,3 \mu \mathrm{m}$ e pressão transmembrana de 1,5 bar. O suco permeado apresentou-se límpido, isento de polpa e com qualidade e sanidade microbiológica. Tais resultados comprovaram a eficiência da microfiltração para clarificação e estabilização de sucos de frutas.
\end{abstract}

PALAVRAS-CHAVE: ENZIMAS; MICROFILTRAÇÃO; MARACUJÁ.

* Discentes, Departamento de Tecnologia de Alimentos, Universidade Federal Rural do Rio de Janeiro, Seropédica, RJ.

** Eng. de Alimentos, M.Sc. em Ciência e Tecnologia de Alimentos, Embrapa Agroindústria de Alimentos, Rio de Janeiro, RJ.

*** Eng. Química, D.Sc. em Tecnologia de Alimentos, Embrapa Agroindústria de Alimentos, Rio de Janeiro, RJ.

**** Eng. Química, D.Sc. em Engenharia Química, Embrapa Agroindústria de Alimentos, Rio de Janeiro, RJ (e-mail: Icabral@ctaa.embrapa.br). 


\section{INTRODUÇÃO}

O maracujá, fruto nativo das Américas Central e do Sul, é cultivado em países de climas subtropical e tropical. Apenas o maracujá amarelo (Passiflora edulis f. flavicarpa) e o maracujá roxo (Passiflora edulis Sims) são cultivados comercialmente, apesar de várias espécies serem conhecidas. O Brasil, mesmo sendo um dos maiores produtores de frutas do mundo, tem participação ainda muito pequena no mercado internacional. Da produção brasileira de maracujá, 53\% é destinada ao consumo interno in natura e $46 \%$ para a indústria de sucos e derivados (BRIGNANI NETO, 2002).

O suco de maracujá caracteriza-se pela complexidade de aromas voláteis e sabor exótico. A pasteurização constitui o método de conservação mais usual do suco, porém o alto conteúdo de amido dificulta a troca de calor e pode provocar a sua gelatinização. Além disso, o suco é submetido à altas temperaturas que podem reduzir seu sabor de fresco devido à termossensibilidade dos compostos aromáticos.

A tecnologia de membrana tem sido avaliada como alternativa para reduzir as perdas sensoriais e nutricionais que podem ocorrer nos processos comumente utilizados para conservação, clarificação e concentração de sucos de frutas (VAILLANT et al., 1999; SÁ, MOTA e CABRAL, 2003). A microfiltração, mais especificamente, vem sendo aplicada para clarificação e redução da carga microbiana de sucos de frutas e bebidas (CHERYAN, 1998; CARNEIRO et al., 2002; MATTA, MORETTI e CABRAL, 2004). O suco integral é separado em duas frações, ou seja, a polpa fibrosa concentrada e a fração clarificada isenta de polpa e de microrganismos. O suco clarificado pode ser utilizado em formulação de refrescos e bebidas prontas para consumo, repositores eletrolíticos, refrigerantes carbonatados ou como insumo na indústrias de sorvetes, geléias, etc. (WOLKOFF et al., 2003). Por outro lado, a fração retida pela membrana apresenta características físico-químicas muito similares às do suco integral, podendo ser utilizada como insumo nas indústrias processadoras de suco (PRESTE et al., 2003).

As vantagens da microfiltração sobre os processos tradicionais incluem a produção de suco límpido e claro, com retenção de enzimas pela 
membrana em função do tamanho de poro da mesma. O tratamento térmico do suco pode ser minimizado e o suco ser esterilizado a frio, caso sejam utilizados processamento e envase assépticos (GIRARD e FUKUMOTO, 2000).

O suco de maracujá integral apresenta alto teor de polpa e elevada viscosidade, o que diminui a eficiência da microfiltração. Isso ocorre pelos baixos valores de fluxo permeado (alta viscosidade) e pela formação de camada de material retido na membrana, aumentando a resistência à transferencia de massa e, conseqüentemente, diminuindo o fluxo através na membrana ao longo do processo (VAILLANT et al., 1999).

Para melhorar a eficiência da microfiltração de sucos de frutas tem sido avaliada a introdução da etapa de hidrólise enzimática do produto. Tal etapa visa degradar os sólidos em suspensão e hidrolisar macromoléculas solúveis, reduzindo a viscosidade e o teor de polpa.

Este trabalho teve como objetivo aumentar a eficiência da clarificação de suco de maracujá, mediante combinação dos processos de microfiltração e tratamento enzimático.

\section{MATERIAL E MÉTODOS}

O suco de maracujá integral foi obtido a partir da fruta fresca em despolpadeira horizontal, peneira de $0,5 \mathrm{~mm}$, sendo mantido congelado $\mathrm{a}-18^{\circ} \mathrm{C}$ até sua utilização.

Foram utilizados na hidrólise, três preparados enzimáticos comerciais: Pectinex Ultra SP L, Thermamyl Liquid 60 (Novo Nordisk) e Biopectinase MB (Quest International), com atividades pectinolítica, amilolítica e celulolítica, respectivamente (Tabela 1). Para a definição da concentração de cada enzima foram elaborados dois planejamentos fatoriais, sempre em duplicata (BOX, HUNTER e HUNTER, 1978). No primeiro delineamento utilizou-se a combinação das três enzimas conforme apresentado na Tabela 2. No segundo delineamento foi avaliada a combinação de duas enzimas em três níveis de concentração, sendo a enzima Biopectinase MB utilizada nas concentrações de 0, 150 e 300 ppm e a enzima Thermamyl Liquid 60 ( $\alpha$-amilase) nas concentrações de 0, 40 e 80 ppm. 


\section{TABELA 1 - ATVIDADE ENZIMÁTICA DAS PREPARAÇÕES ENZIMÁTICAS: PECTINEX ULTRA SP L, THERMAMYL LIQUID 60 E BIOPECTINASE MB}

\begin{tabular}{lccc}
\hline Atividade $(\mathrm{U} / \mathrm{mL})$ & $\begin{array}{c}\text { Pectinex Ultra SP } \\
\text { Loligalacturonase }\end{array}$ & $\begin{array}{c}\text { Biopectinase } \\
\text { MB }\end{array}$ & $\begin{array}{c}\text { Thermamyl Liquid } \\
60\end{array}$ \\
\hline Celulase cristalina & 279,6 & 2084,6 & 50,8 \\
Celulase Cx & 1,3 & 18,8 & 1,0 \\
Xilanase & 27,2 & 335,2 & 0,0 \\
$\alpha$-amilase & 158,5 & 285,5 & 15,2 \\
\hline
\end{tabular}

TABELA 2 - PLANEJAMENTO FATORIAL UTILIZADO PARA DEFINIÇÃO DA CONCENTRAÇÃO DAS ENZIMAS UTILIZADAS NO TRATAMENTO ENZIMÁTICO DE SUCO DE MARACUJÁ

\begin{tabular}{lcccccc}
\hline TE $^{*}$ & $\mathrm{~B}$ & $\mathrm{P}$ & $\mathrm{T}$ & $\mathrm{B}$ & $\mathrm{P}$ & $\mathrm{T}$ \\
\hline 1 & -1 & -1 & -1 & 0 & 0 & 0 \\
2 & -1 & -1 & 0 & 150 & 0 & 0 \\
3 & -1 & -1 & 1 & 300 & 0 & 0 \\
4 & -1 & 0 & -1 & 0 & 0 & 20 \\
5 & -1 & 0 & 0 & 150 & 0 & 20 \\
6 & -1 & 0 & 1 & 300 & 0 & 20 \\
7 & -1 & 1 & -1 & 0 & 0 & 40 \\
8 & -1 & 1 & 0 & 150 & 0 & 40 \\
9 & -1 & 1 & 1 & 300 & 0 & 40 \\
10 & 0 & -1 & -1 & 0 & 150 & 0 \\
11 & 0 & -1 & 0 & 150 & 150 & 0 \\
12 & 0 & -1 & 1 & 300 & 150 & 0 \\
13 & 0 & 0 & -1 & 0 & 150 & 20 \\
14 & 0 & 0 & 0 & 150 & 150 & 20 \\
15 & 0 & 0 & 1 & 300 & 150 & 20 \\
16 & 0 & 1 & -1 & 0 & 150 & 40 \\
17 & 0 & 1 & 0 & 150 & 150 & 40 \\
18 & 0 & 1 & 1 & 300 & 150 & 40 \\
19 & 1 & -1 & -1 & 0 & 300 & 0 \\
20 & 1 & -1 & 0 & 150 & 300 & 0 \\
21 & 1 & -1 & 1 & 300 & 300 & 0 \\
22 & 1 & 0 & -1 & 0 & 300 & 20 \\
23 & 1 & 0 & 0 & 150 & 300 & 20 \\
24 & 1 & 0 & 1 & 300 & 300 & 20 \\
25 & 1 & 1 & -1 & 0 & 300 & 40 \\
26 & 1 & 1 & 0 & 150 & 300 & 40 \\
27 & 1 & 1 & 1 & 300 & 300 & 40 \\
\hline & & & & & &
\end{tabular}

${ }^{*} \mathrm{TE}=$ Tratamento enzimático.

$\mathrm{B}=$ Biopectinase $; \quad \mathrm{P}=$ Pectinex Ultra SP; $\mathrm{T}=$ Thermamyl. 
A hidrólise foi realizada em shaker com frascos cônicos de $500 \mathrm{~mL}$, nos quais o suco foi aquecido a $30^{\circ} \mathrm{C}$, sendo adicionados os preparados enzimáticos nas concentrações estabelecidas no delineamento. $O$ suco foi mantido por uma hora a $30^{\circ} \mathrm{C}$, com agitação constante. A reação foi inativada, aquecendo-se a mistura por 20 minutos a $70^{\circ} \mathrm{C}$. Nos dois delineamentos, a condição 1 refere-se ao suco sem adição de enzima, mas submetido à todas as condições de reação (branco).

Definiu-se a condição de hidrólise a partir da análise dos resultados em programa estatístico (STATSOFT, 1998). Após definição da melhor condição de hidrólise enzimática do suco de maracujá, o processo de microfiltração associado ao pré-tratamento enzimático do suco de maracujá foi avaliado em escala piloto. Foram realizados três experimentos de microfiltração, sob as mesmas condições.

Utilizou-se sistema em escala piloto, para a microfiltração com membrana do tipo tubular e porosidade de $0,3 \mu \mathrm{m}$, área total de permeação de $0,05 \mathrm{~m}^{2}$, com pressão transmembrana de 1,5 bar e temperatura de $25^{\circ} \mathrm{C}$. Nesse caso, o tratamento enzimático foi realizado em vaso multi-propósito Armfield FT 40 (capacidade de 20 L) com controlador de temperatura e de agitação.

O suco de maracujá integral, os produtos da reação enzimática, o suco alimentado à membrana, o suco retido e o suco permeado foram submetidos à determinações físico-químicas e bioquímica.

Determinaram-se se a acidez titulável total (por titulação com hidróxido de sódio, usando fenolftaleína como indicador), o teor de sólidos solúveis em refratômetro (modelo Bellingham \& Stanley Limited), e o pH em potenciômetro (Metronal E120) (AOAC, 1997).

A viscosidade foi avaliada em reômetro de cilindros concêntricos (Rheomat 30), acoplado a banho termostático para controle da temperatura (MATTA, CABRAL e MORETT, 2000).

Determinou-se o teor de polpa por pesagem, após a centrifugação do suco a 4000 rpm por 15 minutos.

A concentração de carotenóides totais foi determinada por extração com n-hexano e leitura em espectrofotômetro (LAMBDA 10 - PERKIN 
ELMER) a $470 \mathrm{~nm}$, segundo metodologia proposta por GOODWIN (1976).

O suco de maracujá microfiltrado foi avaliado quanto à sua qualidade microbiológica mediante análises de contagens de bolores e leveduras, bactérias mesófilas, coliformes fecais e totais e da presença de Salmonella, segundo SIQUEIRA (1995).

\section{RESULTADOS E DISCUSSÃO}

Os resultados físico-químicos das 27 amostras de suco hidrolisado no primeiro planejamento experimental (Tabela 3) não evidenciaram influência dos tratamentos enzimáticos nos valores de $\mathrm{pH}$, acidez titulável e teor de sólidos solúveis em relação a amostra sem tratamento (suco integral).

\section{TABELA 3 - CARACTERIZAÇÃO FÍSICO-QUÍMICA MÉDIA DOS HIDROLISADOS OBTIDOS NO $1^{\circ}$ PLANEJAMENTO EXPERIMENTAL}

\begin{tabular}{lcccccc}
\hline & $\mathrm{pH}$ & $\begin{array}{c}\text { Acidez } \\
(\% \text { ac.c trico })\end{array}$ & Brix & $\begin{array}{c}\text { Sacarose } \\
(\mathrm{g} / 100 \mathrm{~g})\end{array}$ & $\begin{array}{c}\text { Glicose } \\
(\mathrm{g} / 100 \mathrm{~g})\end{array}$ & $\begin{array}{c}\text { Frutose } \\
(\mathrm{g} / 100 \mathrm{~g})\end{array}$ \\
\hline $\begin{array}{l}\text { Sucos } \\
\text { hidrolisados }\end{array}$ & $2,9 \pm 0,1$ & $4,8 \pm 0,1$ & $13,4 \pm 0,3$ & $3,9 \pm 0,8$ & $2,5 \pm 0,6$ & $2,6 \pm 0,7$ \\
Suco integral & 2,9 & 4,7 & 14,0 & 4,6 & 2,3 & 2,6 \\
\hline
\end{tabular}

Verificou-se diferença significativa no teor de polpa e na viscosidade aparente dos sucos entre os tratamentos. O valor da viscosidade aparente variou de 10,8 a 4,7 mPa.s e o teor de polpa apresentou redução de 6 a 8,5\% em relação ao teor de polpa do suco integral (Figura 1).

A concentração da enzima Pectinex não influenciou os valores do teor de polpa e da viscosidade aparente dos hidrolisados obtidos (Figura 2), assim elaborou-se o segundo planejamento fatorial. Nesse, a enzima Pectinex não foi utilizada, sendo a enzima Thermamyl Liquid 60 ( $\alpha$-Amilase) testada em nível de concentração maior, visando ampliar a redução da viscosidade do suco de maracujá. 
FIGURA 1 - VISCOSIDADE E TEOR DE POLPA DE MARACUJÁ DAS AMOSTRAS SUBMETIDA À DIFERENTES CONDIÇÕES DE TRATAMENTO ENZIMÁTICO

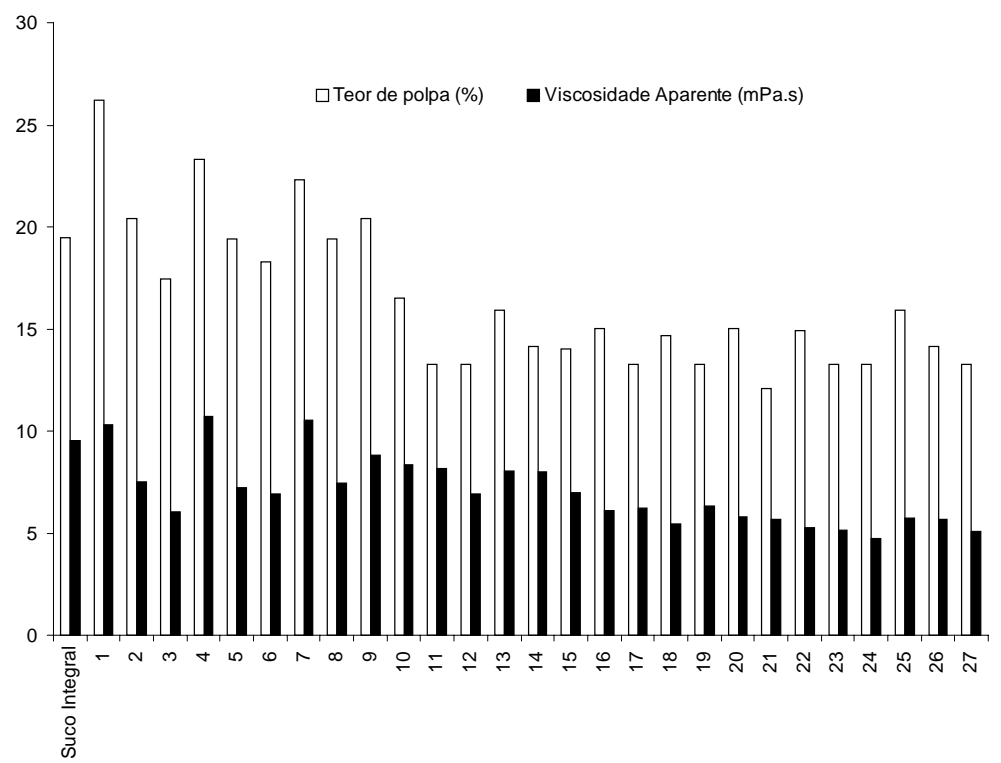

Tratamento

FIGURA 2 - EFEITO DA CONCENTRAÇÃO DAS ENZIMAS BIOPECTINASE E PECTINEX SOBRE O TEOR DE POLPA (A) E A VISCOSIDADE (B) DO SUCO DE MARACUJÁ

Fitted Surface; Variable: POLPA

A

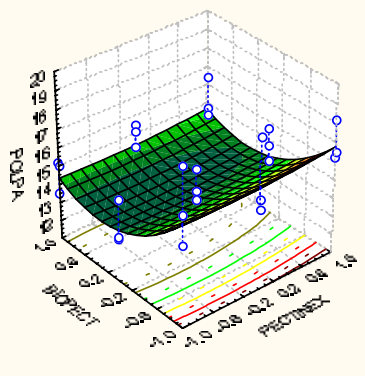


B

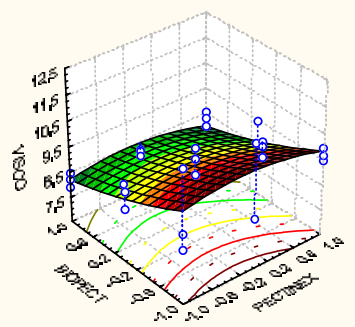

A avaliação físico-química dos tratamentos realizados no segundo delineamento está apresentada na Tabela 4. A maior redução do teor de polpa e da viscosidade aparente em relação ao suco não-hidrolisado (condição 1) foi verificada ao se utilizar 300 ppm de Biopectinase e 40 ppm de Thermamyl Liquid 60 (condição 8). O efeito da concentração das duas enzimas sobre os dois parâmetros está apresentado nas Figuras 3 e 4. Verificou-se que os menores valores da viscosidade e do teor de polpa estão localizados na região em que a Biopectinase MB encontrava-se com a concentração máxima e a enzima Thermamyl Liquid 60 com concentração intermediária.

\section{TABELA 4 - CARACTERIZAÇÃO FÍSICO-QUÍMICA DOS HIDROLISADOS OBTIDOS NO $2^{\circ}$ PLANEJAMENTO EXPERIMENTAL}

\begin{tabular}{c|c|c|c|c|c|c|c}
\hline Tratamento & B & T & $\begin{array}{c}\text { Viscosidade } \\
\text { (m.Pa.s) }\end{array}$ & $\begin{array}{c}\text { Teorde } \\
\text { Polpa } \\
(\%)\end{array}$ & $\mathrm{pH}$ & $\begin{array}{c}\text { Acidez } \\
\text { (\% ac. c trico) }\end{array}$ & $\begin{array}{c}\text { Slidos } \\
\text { Soløeis } \\
\text { ("B rix) }\end{array}$ \\
\hline 1 & -1 & -1 & 8,4 & 16,4 & 3,0 & 3,8 & 12,8 \\
2 & -1 & 0 & 7,9 & 16,5 & 3,0 & 4,1 & 13,0 \\
3 & -1 & 1 & 7,6 & 16,5 & 3,0 & 3,8 & 12,4 \\
4 & 0 & -1 & 7,0 & 15,4 & 3,0 & 4,0 & 13,0 \\
5 & 0 & 0 & 6,2 & 12,6 & 3,0 & 4,0 & 13,0 \\
6 & 0 & 1 & 6,7 & 16,5 & 3,0 & 3,8 & 12,7 \\
7 & 1 & -1 & 6,3 & 14,4 & 3,0 & 3,9 & 12,9 \\
8 & 1 & 0 & 6,0 & 13,0 & 3,0 & 3,9 & 13,0 \\
9 & 1 & 1 & 6,5 & 14,9 & 3,0 & 3,9 & 12,4 \\
\hline
\end{tabular}

$\mathrm{B}=$ Biopectinase $; \mathrm{T}=$ Thermamyl Liquid 60 . 
FIGURA 3 - EFEITO DA CONCENTRAÇÃO DAS ENZIMAS BIOPECTINASE E THERMAMYL LIQUID 60 (aAMILASE) SOBRE O TEOR DE POLPA (A) E A VISCOSIDADE (B) DO SUCO DE MARACUJÁ

Fitted Surface; Variable: POLPA

2 3-level factors, 1 Blocks, 9 Runs; MS Residual=1,008067

DV: POLPA

A

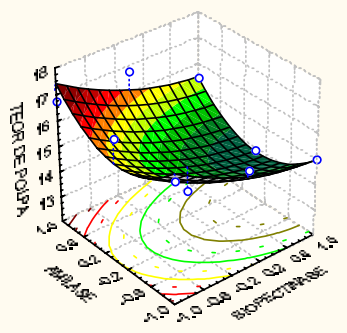

Fitted Surface; Variable: VISCOSID

2 3-level factors, 1 Blocks, 9 Runs; MS Residual =,0851611

DV: VISCOSID

B

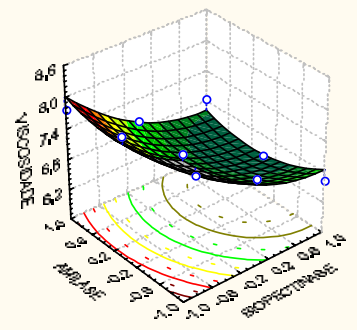

As duas enzimas apresentaram efeito positivo. A atividade pectinolítica e celulolítica presente na Biopectinase permite a hidrólise de polissacarídios solúveis e sólidos suspensos, constituídos por polissacarídios da parede celular. Já a ação amilolítica da Thermamyl age na hidrólise do amido, diminuindo a viscosidade do suco. VAILLANT et al. (2001), estudando a hidrólise de suco de maracujá, sugeriram concentrações mais altas de preparações enzimáticas para a liquefação do suco devido ao seu alto teor de amidos e sólidos em suspensão. 
O processo de microfiltração manteve fluxo médio de permeado de $16 \mathrm{~L} / \mathrm{hm} 2$. Esse fluxo, inicialmente igual a $30 \mathrm{~L} / \mathrm{hm} 2$ apresentou 0 comportamento clássico dos processos de microfiltração de sucos polposos. A polarização de concentração provoca a queda inicial do fluxo permeado e o "fouling", resultado do acúmulo de material sobre a superfície da membrana, reduz o fluxo ao longo do tempo de processo (Figura 4).

\section{FIGURA 4 - EVOLUÇÃO DO FLUXO PERMEADO REFERENTE A TRÊS REPETIÇÕES (M1, M2 E M3) DO PROCESSO DE MICROFILTRAÇÃO DE SUCO DE MARACUJÁ COM TRATAMENTO ENZIMÁTICO 300 ppm DE BIOPECTINASE E 40 ppm DE AMILASE}

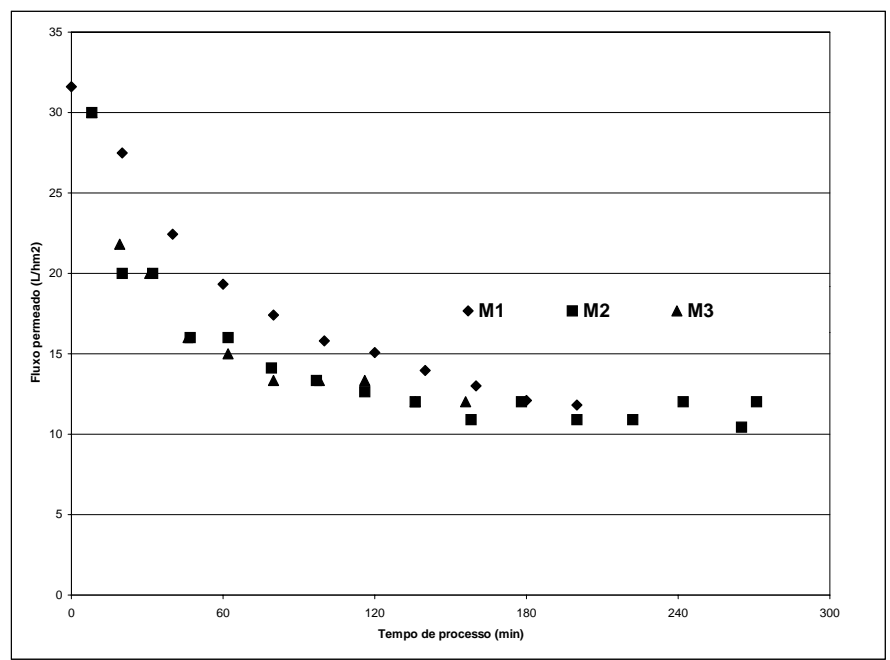

A Tabela 5 apresenta a caracterização média das quatro frações, suco integral, suco hidrolisado (alimentação), suco retido e suco permeado (clarificado) nos três processos realizados. O suco permeado apresentou pequeno decréscimo nos valores de sólidos solúveis, resultado da retenção pela membrana de macromoléculas nãohidrolizadas. O permeado apresentou-se límpido e claro. Em relação ao teor de carotenóides foi verificado que o tratamento enzimático provocou aumento nesse parâmetro. Mas, após a microfiltração, 
observou-se diminuição da cor amarela no suco clarificado. Tal fato foi relacionado ao baixo teor de carotenóides nos sucos permeados, indicando que a membrana de microfiltração reteve esses componentes.

\section{TABELA 5 - CARACTERIZAÇÃO FÍSICO-QUÍMICA MÉDIA DOS TRÊS PROCESSOS DE MICROFILTRAÇÃO DE SUCO DE MARACUJÁ}

\begin{tabular}{ccccccc}
\hline Suco & $\begin{array}{c}\text { Viscosidade } \\
\text { (m.Pa.s) }\end{array}$ & $\begin{array}{c}\text { Teor de } \\
\text { polpa } \\
(\% \mathrm{p} / \mathrm{p})\end{array}$ & $\mathrm{pH}$ & $\begin{array}{c}\text { Acidez } \\
\text { (\% ac. } \\
\text { c trico) }\end{array}$ & $\begin{array}{c}\text { S lidos } \\
\text { solø/eis } \\
\text { "Brix }\end{array}$ & $\begin{array}{c}\text { Caroten ides } \\
\text { totais } \\
(\mathrm{mg} / 100 \mathrm{~g})\end{array}$ \\
\hline Integral & 7,53 & 17,29 & 3,05 & 4,38 & 13,55 & 0,87 \\
Alimenta a 0 & 4,41 & 10,43 & 3,04 & 4,22 & 13,13 & 1,09 \\
Retido & 3,54 & 10,31 & 3,03 & 4,03 & 13,23 & 1,02 \\
Permeado & 1,22 & 0,00 & 3,04 & 3,90 & 11,65 & 0,17 \\
\hline
\end{tabular}

Tratamento enzimático: 300 ppm de biopectinase e 40 ppm de Thermamyl Liquid 60.

A avaliação microbiológica do suco de maracujá microfiltrado revelou que as amostras estavam aptas para o consumo humano (BRASIL, 2001).

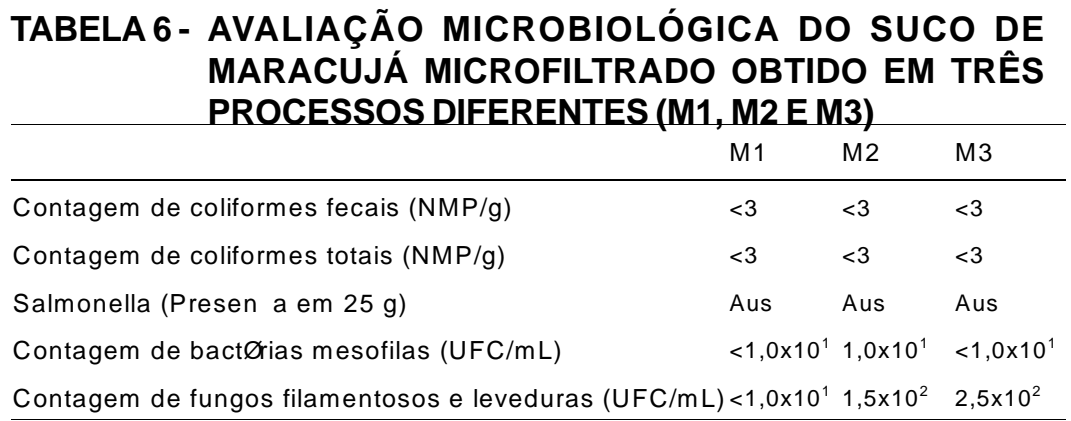

\section{CONCLUSÃO}

Os resultados obtidos neste trabalho evidenciaram efeito positivo das enzimas Thermamyl ( $\alpha$-Amilase) e Biopectinase MB no suco de 
maracujá. A enzima Pectinex não apresentou efeito significativo na redução do teor de polpa e da viscosidade aparente do suco de maracujá. A melhor condição da hidrólise foi 300 ppm de Biopectinase e 40 ppm de Thermamyl Liquid 60. Após o tratamento enzimático não foram verificadas variações no $\mathrm{pH}$ e no teor sólidos solúveis. Entretanto, a viscosidade e o teor de polpa foram reduzidos e contribuíram para melhorar a eficiência do processo, avaliada a partir da determinação do fluxo permeado. A microfiltração associada à hidrólise enzimática do suco de maracujá resultou em produto límpido, isento de polpa e com qualidade e sanidade microbiológica.

\section{Abstract \\ IMPROVEMENT IN THE EFFICIENCY OF PASSION FRUIT JUICE CLARIFICATION BY THE COMBINATION OF MICROFILTRATION AND ENZYMATIC PROCESSES}

This work had as objective the obtention of clarified passion fruit juice by using the microfiltration technique. A step of enzymatic treatment was introduced before microfiltration, aiming to enhance process efficiency by reduction of viscosity and pulp content of the juice. Three different hidrolytic enzymes were tested in three concentration levels. The results didn't demonstrate significant differences in Brix, $\mathrm{pH}$ and acidity of the hidrolyzed juice samples in relation to the concentrated juice. Positive effect was observed in the action of the enzymes in the reduction of viscosity and pulp content. The microfiltration was realized in a tubular membrane system with average size of the pore equivalent to $0.3 \mathrm{~m}$ and transmembrane pressure of 1.5 bar. The permeate juice was clear, free from pulp and with good micribiological quality. Such results proved the efficiency of microfiltration for clarification and stabilization of fruit juices.

KEY-WORDS: ENZYMES; MICROFILTRATION; PASSION FRUIT.

\section{REFERÊNCIAS}

1 AOAC. American Official of Analytical Chemists. Official methods of analysis of AOAC international. $17^{\text {th }} \mathrm{ed}$. Washington, 1997.

2 BOX, G.E.P.; HUNTER, W.G.; HUNTER, J.S. Statistics for experiment: an introduction to design, data analysis and model building. New York: Wiley, 1978.

3 BRIGNANI NETO, F. Produção integrada de maracujá. Biológico, 
São Paulo, v. 64, n. 2, p. 95-197, 2002.

4 CARNEIRO, L.C.; SÁ, I.S.; GOMES, F.S.; MATTA, V. M. CABRAL, L.M.C. Cold sterilization and clarification of pineapple juice by tangential microfiltration. Desalination, v. 148, p. 93-98, 2002.

5 CHERYAN, M. Ultrafiltration and microfiltration handbook. Lancaster: Technomic Pub., 1998. 527 p.

6 GIRARD, B.; FUKUMOTO, L.R. Membrane processing of fruit juice and beverages: a review. Critical Reviews on Food Science and Nutrition, v.40, n.2, p.91-157, 2000.

7 GOODWIN, T.W. Chemistry and biochemistry of plants pigments. $2^{\text {nd }}$ ed. London: Academic Press, 1976. v.2.

8 MATTA, V.M.; CABRAL, L.M.C.; SILVA, F.C.; MORETTI, R.H. Rheological behavior of West Indian cherry pulp with and without enzymatic treatment. Brazilian Journal of Food Technology, v.3, p.59-64, 2000.

9 MATTA, V.M.; MORETTI, R.H.; CABRAL, L.M.C. Microfiltration and reverse osmosis for clarification and concentration of acerola juice. Journal of Food Engineering, v.61, n.4, p.477-482, 2004.

10 PESTRE, L.R.; SILVA, L.F.; MATTA, V.M.; CABRAL, L.M.C. Avaliação da fração retida durante a microfiltração de suco de maracujá. In.: SIMPÓSIO LATINO AMERICANO DE CIÊNCIA DE ALIMENTOS, 5., 2003, Campinas, Resumos... Campinas: UNICAMP, 2003. CDRom.

11 SÁ, I. S.; MATTA, V.M.; CABRAL, L.M.C. Concentração de suco de abacaxi através dos processos com membranas. Brazilian Journal of Food Technology, v. 6, p. 53-62, 2003.

12 SIQUEIRA, R.S. Manual de microbiologia de alimentos. Rio de Janeiro. EMBRAPA, 1995. 159 p.

13 STATSOFT INC. Statistica for windows: release $5^{\circ}$ A. Tulsa, USA, 1998.

14 VAILLANT, F.; MILLAN, P.; O’BRIEN, G.; DORNIER, M.; DECLOUX, M.; REYNES, M. Cross flow microfiltration of passion fruit juice partial enzymatic liquefaction. Journal of Food Engineering, n.42, p.215224, 1999.

15 VAILLANT, F.; MILLAN, P.; DORNIER, M.; DECLOUX, M.; REYNES, M. Strategy for economical optimization of the clarification of pulpy fruit 
juices using cross flow microfiltration. Journal of Food Engineering, v.48, p.83-90, 2001.

16 WOLKOFF, D.B.; SILVA, L.F.M.; MORETTI, R.H.; MATTA, V.M. Avaliação da estabilidade de bebida repositora hidroeletrolítica à base de sucos microfiltrados de acerola e caju. In: CONGRESO IBEROAMERICANO DE INGENIERÍA DE ALIMENTOS, 4., 2003, Valparaíso, Chile. Programas e resumos... Valparaíso: UTFSM, 2003. p. 199. 